\title{
A parentetização: estratégia de construção textual-interativa do chat educacional ${ }^{1}$ \\ Bracketing as textual-interactive construction strategy of the educational chat
}

Crisciene Lara Barbosa-Paiva*

Universidade Estadual Paulista - UNESP

Araraquara - São Paulo / Brasil

RESUMO: Este artigo descreve, sob a Perspectiva Textual-Interativa, tal como definida por Jubran (2006a), a parentetização (JUBRAN, 1996, 2006b) em uma conversação síncrona mediada por computador, voltada para a esfera educacional, escrita em espanhol por participantes brasileiros - o chat educacional. Observamos que a parentetização constitui-se como uma das regularidades dos processos de elaboração textual. Trata-se, portanto, de uma estratégia de construção textual do chat educacional bastante produtiva.

PALAVRAS-CHAVE: Perspectiva textual-interativa, estratégia de construção textual, parentetização, chat, conversação escrita em espanhol e mediada por computador.

ABSTRACT: This paper describes bracketing (JUBRAN, 1996, 2006b), based on the text-interactive perspective (JUBRAN, 2006a, 2007), in data from a written Spanish conversation mediated by computer in a learning virtual environment - the educational chat - for Brazilians. We observe that bracketing is one of the regularities in the text construction in the chat analyzed. We verifity that bracketing is, therefore, a strategy of text construction, and a very productive one.

KEYWORDS: Text-interactive perspective, strategy of text construction, bracketing, chat, written Spanish conversation mediated by computer.

* crisbarbosa.paiva@gmail.com

${ }^{1}$ Este artigo faz parte de minha pesquisa de doutorado em desenvolvimento, sob a orientação da Profa. Dra. Anise D’Orange Ferreira, na Universidade Estadual Paulista Júlio de Mesquita Filho (UNESP - Araraquara), com bolsa do CNPq. O presente artigo aprofunda um aspecto da minha dissertação de mestrado, intitulada "Estratégias de construção textual do chat escrito em espanhol como língua estrangeira”, defendida na mesma instituição, em 2010, sob a orientação da Profa. Dra. Ucy Soto, com bolsa da CAPES-DGU (Espanha) e do CNPq (Brasil). 


\section{Introdução}

A internet nos oferece uma "alternativa nova para as modalidades em que a comunicação humana pode ocorrer" (CRYSTAL, 2005, p. 76). Essa alternativa nova é denominada comunicação mediada por computador (doravante CMC) ou comunicação eletrônica (CRYSTAL, 2005; MARCUSCHI, 2008), que abrange todos os formatos de comunicação e os respectivos gêneros que surgem nesse contexto (MARCUSCHI, 2008). Esses gêneros textuais emergentes da tecnologia digital, desenvolvidos a partir das três últimas décadas do século 20, são bastante variados e entre eles podemos mencionar o chat educacional, que permite ao aluno interagir de forma síncrona, em distintos contextos, em situações reais de uso da linguagem e em interações com pessoas localizadas geograficamente distantes.

Observamos que estudos que envolvem estratégias de construção textual estão voltados para a descrição do português em texto falado e em texto escrito prototípico, sem que haja menção ou descrição de estratégias de construção textual nas novas modalidades de comunicação trazida pela internet, principalmente, sem observar a CMC em contexto de ensino e aprendizagem de línguas. Rodríguez Illera e Escofet Riog (2008) ressaltam a grande complexidade que é pensar a comunicação em ambientes virtuais. Essa complexidade aumenta se tivermos em conta uma perspectiva educativa e, especialmente, se nos voltarmos para uma interação realizada em língua estrangeira (como é o caso dos corpora que serão analisados aqui neste artigo).

Como parte de uma pesquisa mais ampla em que investigamos a construção textual do chat educacional, uma conversação síncrona, por escrito, mediada por computador, voltada para a esfera educacional, delimitamo-nos, no presente artigo, a apresentar uma das estratégias de construção textual do chat educacional: a parentetização (JUBRAN, 1996a, 1996b, 2006a, 2006b), sob os fundamentos teórico-metodológicos da Perspectiva Textual-Interativa, ${ }^{2}$ conforme expõe Jubran (2006a, 2007). As sessões de chat educacional analisadas foram realizadas essencialmente por escrito, em tempo real, em

\footnotetext{
${ }^{2}$ No interior do Projeto de Gramática do Português Falado (PGPF), coordenado por Ataliba Teixeira de Castilho, constituiu-se o Grupo do Texto, sob responsabilidade de Ingedore Koch. Esse grupo formulou uma proposta teórica para o estudo do texto falado, adotando uma perspectiva textual-interativa (JUBRAN, 2006a, 2007). Ressaltamos que os princípios dessa perspectiva estão expostos, resumidamente, neste artigo.
} 
língua espanhola por participantes brasileiros. Este artigo contribui para explicitar um dos procedimentos de elaboração textual e uma das atividades de formulação de um corpus ainda pouco explorado e que faz parte de um contexto em que, de acordo com Crystal (2005), "as opções de comunicação do usuário são determinadas pela natureza do hardware necessário para se obter acesso à internet. Assim, uma série de caracteres em um teclado determina a capacidade linguística produtiva" (p. 80).

Entendemos por estratégias de construção textual as atividades ou os processos de construção textual, por exemplo, a parentetização. Essa denominação de estratégias se fundamenta em trabalhos realizados levando em conta a perspectiva textual-interativa adotada, por exemplo, em Koch (2002) no qual se afirma que a inserção está entre as principais estratégias de processamento do texto falado. Ressaltamos que consideramos estratégias de construção textual sinônimas de "procedimentos de construção textual", já que Jubran (2007) entende que "são concebidos como procedimentos de construção textual fatos de diversa ordem", por exemplo, a parentetização (p. 316, negritos nossos).

\section{Fundamentação teórica}

\section{Perspectiva textual-interativa}

A adoção de uma Perspectiva Textual-Interativa, neste artigo, tanto como opção teórica quanto analiticamente para a descrição da estratégia de construção textual-interativa da parentetização, no chat educacional, requer, em decorrência dessa opção, uma definição dos principais conceitos que fundamentam essa perspectiva.

A perspectiva textual-interativa concebe a linguagem como uma "forma de ação, uma atividade verbal exercida entre pelo menos dois interlocutores, dentro de uma localização contextual, em que um se situa reciprocamente em relação ao outro, levando em conta circunstâncias de enunciação", conforme expõe Jubran (2006a, p. 28). A linguagem é vista como manifestação de uma competência comunicativa, definível, de acordo com Jubran (2006a), como "capacidade de manter a interação social, mediante a produção e entendimento de textos que funcionam comunicativamente" (p. 28).

Essa perspectiva considera que os fatores interacionais são constitutivos do texto, sendo, assim, inerentes à expressão linguística (JUBRAN, 2006a; 2007). De acordo com Jubran (2006a), "as condiçóes comunicativas que 
sustentam a ação verbal inscrevem-se na superfície textual, de modo que se observam marcas do processamento formulativo-interacional na materialidade linguística do texto" (p. 29).

A autora (2006a) salienta que em uma descrição textual-interativa é fundamental que o produto linguístico sob análise seja tratado "dentro do contexto sociocomunicativo do qual emerge, a partir das marcas concretas que a situação enunciativa imprime nos enunciados" (p. 29, negritos nossos).

Para Jubran (2007), o texto, enquanto realização efetiva da atividade interacional, "emerge de um jogo de atuação comunicativa", que se projeta na sua construção, constituindo-se, assim, o lugar de identificação de pistas indicadoras de regularidades de um sistema de desempenho verbal. O texto é, então, estabelecido como "objeto de estudos" dessa perspectiva, assegurada sempre a sua inserção na instância de produção, para a investigação de seus procedimentos de construção (como a parentetização). Essa perspectiva deve, portanto, "apontar regularidades relacionadas ao processamento dos procedimentos de elaboração textual, aferindo o caráter sistemático deles pela sua recorrência em contextos definidos, pelas suas marcas formais que o caracterizam" (JUBRAN, 2007, p. 316).

\section{Processos constitutivos do texto}

Castilho (1998) menciona três processos que constituem o texto e a sentença: a construção por ativação, a construção por reativação e a construção por desativação.

A construção por ativação, processo central de constituição da língua, consiste na seleção de palavras para a constituição do texto e suas unidades e das sentenças e suas estruturas, dando-lhes uma representação fonológica.

A construção por reativação, "processamento anafórico", é a volta ao que foi dito, por meio da retomada ou repetição de formas ou de conteúdos. A repetição (a recorrência de expressões) e a paráfrase (recorrência de conteúdos) constituem as duas manifestações da construção por reativação.

A construção por desativação constitui o processo de ruptura na elaboração do texto e da sentença: o abandono de segmentos textuais, as digressões, os parênteses, a ruptura da adjacência por meio de pausas, hesitações, inserção de elementos discursivos, elipses, anacolutos. 


\section{Atividade de formulação}

Como um dos objetivos deste trabalho é estudar uma das atividades de formulação do chat educacional, é relevante definirmos "atividade de formulação".

Para Kock (2003), as atividades de formulação textual são aquelas "que o locutor realiza para estruturar o seu texto de modo que possa ser compreendido pelo interlocutor" (p. 118).

Segundo Fávero, Andrade e Aquino (2006) “o locutor que produz um enunciado não elabora somente uma sequência verbal, mas realiza uma atividade intencional: formular é efetivar atividades que estruturam e organizam os enunciados de um texto" (p. 256, negritos nossos). De acordo com Antos (apudFÁVERO; ANDRADE; AQUINO, 2006), "formular um texto não é só planejá-lo mas também realizá-lo" (p. 256). Fávero, Andrade e Aquino (2006) acrescentam que:

o esforço que o locutor faz para produzir um enunciado se manifesta por traços que ele deixa em seu discurso; isto é, formular um texto não significa simplesmente deixar ao interlocutor a tarefa da compreensão, mas significa deixar, através das marcas, pistas para que ele, interlocutor, se esforce por compreendê-lo (...). (p. 256, negritos nossos).

\section{Estratégia de construção textual-interativa: a parentetização}

A parentetização é referida, genérica e comumente, pelo Grupo de Organização Textual-Interativa como estratégia de construção textual e como atividade de formulação, conforme podemos observar nos apontamentos de Jubran (2006a, 2006b). Neves (2010, p. 165) também concebe o parêntese como estratégia formulativa e acrescenta que o parêntese "é de uma das estratégias de discursivização e de textualização de maior relevância”. Para Castilho (1998), "os parênteses não se constituem num Tópico desviante, (...) pois não dispõem das propriedades de centração e organicidade. Eles têm por isso mesmo menor extensão textual" (p. 80).

O estudo da parentetização pode ser definido de acordo com duas perspectivas de análise: frástica e textual.

$\mathrm{Na}$ primeira abordagem, que tem a frase como limite máximo de análise, os parênteses têm sido definidos como frases independentes, isto é, frases hóspedes, que interrompem a relação sintática da frase na qual estão encaixadas e não apresentam, em relação a ela, uma conexão formal 
nitidamente estabelecida (SCHNEIDER apud JUBRAN, 2006b; 2009). Essa definição de parênteses se baseia exclusivamente em um critério sintático e se limita ao nível frástico: eles aparecem no interior de uma frase de estrutura sintática canônica e essa estrutura não é afetada pelo enunciado encaixado (JUBRAN, 2006b).

Já na abordagem textual, a frase não é delimitada como unidade máxima de análise, mas, sim, os segmentos são recortados tendo como base a categoria de tópico discursivo. Nessa visão, os fatos de parentetização podem eventualmente englobar frases-hóspedes, não se restringindo a elas apenas, uma vez que os parênteses passam a ser definidos por outro critério (não exclusivamente sintático): a categoria de tópico discursivo, formulada pela perspectiva textual-interativa para a definição de uma unidade de análise de estatuto textual. Assim, nessa abordagem textual, os parênteses têm uma constituição formal diversificada.

Jubran (2006b) enfatiza que os parênteses constituem-se como uma "modalidade de inserção", definível como "breves desvios de um tópico discursivo" (p. 303). Assim, os parênteses não afetam a coesão do segmento tópico dentro do qual ocorrem. A autora ressalta que a inserção parentética não apresenta estatuto tópico, porque não constitui uma nova centração, já que não desenvolve outro tópico discursivo dentro do que estava em curso. Nesse sentido, o elemento inserido provoca uma breve suspensão do tópico no qual se encaixa, de forma que não acontece a divisão desse tópico em porções textuais claramente separáveis. Esse elemento inserido interrompe momentaneamente o tópico, retomando-o imediatamente. Nesse caso, temos o esquema:

Tópico A (Suspensão momentânea do tópico A) Continuidade do tópico A.

Adotamos neste trabalho a definição de parentetização exposta por Jubran (1996a, 1996b, 2006a, 2006b). Segundo a autora (2006a), "a parentetização tem por característica a inserção, no segmento tópico, de informações paralelas ao assunto em relevância naquele momento do texto, promovendo um desvio tópico discursivo no qual se encaixam" (p. 35).

Com relação às propriedades identificadoras dos parênteses, o desvio tópico é definido como "encaixe em um segmento tópico de elementos não concernentes ao tópico discursivo desse segmento", de acordo com Jubran (op. cit., p. 305). Para a autora, o desvio tópico constitui-se como o critério primeiro de identificação de inserçôes parentéticas. A análise da parentetização requer uma 
etapa inicial de delimitação do contexto (identificação do tópico discursivo) para que se possa, em uma próxima etapa, observar a suspensão tópica operada pelo encaixe de parênteses no interior desse tópico (contexto). Jubran (1996a, 1996b, 2006b) argumenta ainda que, além desse critério do desvio tópico, há também marcas formais prototípicas de elemento inserido, que funcionam igualmente como critérios de reconhecimento e delimitação de fatos parentéticos.

Os parênteses apresentam um papel relevante no estabelecimento da significação de base informacional, sobre a qual se funda a centração do segmento / contexto. Eles promovem avaliações e comentários laterais sobre o que está sendo dito, e / ou sobre como se diz, e / ou sobre a situação interativa e o evento comunicativo (JUBRAN, 2006b). É por isso que as inserçōes parentéticas "não podem ser consideradas como desvios descartáveis do texto", conforme aponta Jubran (op. cit, p. 305), já que a caracterização do mecanismo de parentetização como "suspensão de um tópico discursivo" ou "desvio tópico" poderia gerar a uma avaliação negativa dessa estratégia de construção textual (JUBRAN, 1996).

Percebemos que Castilho (1998) entende que o parêntese está relacionado ao tópico quando o autor afirma que os parênteses "são atos de fala que constituem pequenos esclarecimentos, comentários, perguntas, etc., fornecendo observações rápidas ao Tópico que se vem desenvolvendo" (p. 81). Já na visão de Jubran (2006b), o desvio tópico e a introdução de dados situacionais se manifestam em graus variáveis, que se correlacionam da seguinte forma:

a) de um lado, os parênteses são menos desviantes do tópico discursivo quando pendem mais para o conteúdo dos enunciados de relevância tópica, esclarecendo-os, exemplificando-os, sem deixarem de sinalizar demandas pragmáticas para a sua ocorrência (JUBRAN, 2006b, p. 325). b) por outro lado, os parênteses são mais desviantes do tópico quando apresentam uma tendência mais acentuada para focalizarem o processo de enunciação, bem como circunstâncias da situação de comunicação, (...) (JUBRAN, 2006b, p. 325).

Tendo em vista que os graus de desvio tópico e os de manifestação de fatores pragmáticos são variáveis, Jubran (2006b) elaborou quatro grandes classes de parênteses, tendo como critério o foco sobre o qual incidem predominantemente os fatos de parentetização: 
Classe (a): parênteses focalizadores da elaboração tópica do texto: esta classe está constituída por parênteses que estão voltados para a elaboração dos tópicos discursivos em curso. Compreende três subclasses:

(1) Parênteses focalizadores do conteúdo tópico: segundo Jubran (1999, 2006b) os parênteses dessa subclasse estão na situação limite de reconhecimento de um segmento textual como parentético ou não, uma vez que "atenuam a propriedade de desvio tópico particularizadora de parentetização, na medida em que, enfocando o conteúdo tópico, mantêm algum traço de aproximação com ele" (JUBRAN, 2006b, p. 328). Dessa forma, de acordo com Jubran (2006b), é por meio das marcas formais do processo parentético que podemos discernir quando um elemento adquire ou não estatuto parentético. As funções dessa subclasse são: exemplificação, esclarecimento, ressalva, retoque e correção.

(2) Parênteses focalizadores da formulação linguística do tópico: os parênteses ligados à formulação linguística do tópico são fragmentos discursivos que se desviam da centração tópica, a fim de colocar em foco o sistema verbal que está sendo usado pelos interlocutores, que, dessa maneira, estão focalizando a própria linguagem. Borillo (apud JUBRAN, 1999) lembra que, nesse caso, é recuperado o sentido que Jakobson atribuiu à função metalinguística. Borillo (1985 apud JUBRAN, 1999) menciona que a concepção de metalinguagem aproxima-se da de metadiscurso, uma vez que é relacionada com o ato de enunciação, dando origem às formulações metalinguísticas (BORILLO apud JUBRAN, 1999). Partindo dessas constataçōes, Jubran (1999, 2006b) agrupa, nessa classe de parênteses, as inserçôes parentéticas que: i) deixam à mostra operações metalinguísticas; ii) pontuam o texto com procedimentos de busca de denominações e de confirmação ou rejeição de escolhas lexicais; iii) o locutor declara ao interlocutor que está processando opçóes lexicais ou dele solicita colaboração para a escolha de denominações.

(3) Parênteses focalizadores da estruturação tópica: da mesma maneira que os parênteses mencionados no item anterior, estes são igualmente metadiscursivos, pois colocam em evidência, no texto, a sua própria estrutura. 
Classe (b): parênteses com foco no locutor: de acordo com Jubran (1999, 2006b), é por meio das inserções parentéticas que o falante se introjeta no texto que produz. Segundo os estudos de Chafe (apud JUBRAN, 1999, 2006b), a inclusão do locutor no texto é expressa linguisticamente por recursos que mostram situações de egoenvolvimento (uso de pronomes de primeira pessoa) e aqueles que mostram o envolvimento do falante com o assunto.

Classe (c): parênteses com foco no interlocutor: nesta classe, os parênteses materializam a presença do interlocutor no texto. Preenchem uma função fática e, por isso, são acentuadamente interacionais. Para Jubran (2006b, p. 345), esses parênteses apresentam um "grau maior de manifestação do processo interativo na superfície textual, relativamente aos parênteses da classe anterior". Apesar disso, os parênteses da classe (c) não deixam de apresentar implicações no que se diz sobre os tópicos discursivos. Nessa classe, os parênteses provocam uma suspensão momentânea do tópico discursivo em curso para colocar em proeminência informações sobre o papel discursivo do interlocutor, seus atributos para exercê-lo e seu envolvimento com o(s) interlocutor(es) do ato comunicativo e com os assuntos tratados (JUBRAN, 1999, 2006b).

Classe (d): parênteses focalizadores do ato comunicativo: os parênteses que integram essa classe (d) promovem um grau máximo de desvio tópico, pois provocam um "apagamento" do tópico discursivo em desenvolvimento para focalizar o ato comunicativo que está em processo. Os parênteses dessa classe colocam em primeiro plano a própria situação de interação verbal e, dessa forma, não apresentam nenhuma concernência com o tópico em curso. Focalizando o ato de comunicação, esses tipos de parênteses quebram o fluxo temático para focar, no interior do texto, dados variados: ruídos ou quaisquer outros fatores que possam atrapalhar o canal físico ou o contato entre interlocutores, contingências necessárias para a realização ou prosseguimento da interação verbal, comentários avaliativos sobre o ato comunicativo em desenvolvimento, entre outros (JUBRAN, 1999, 2006).

Partindo dessas quatro grandes classes de parênteses, Jubran (2006b) verificou que na construção do texto falado houve parênteses com foco no locutor e no interlocutor, isto é, duas classes de parênteses operando ao mesmo tempo.

Para a análise das fronteiras de ocorrência das inserções parentéticas, a autora observa o trecho tópico em que são verificados os parênteses. Segundo Delomier e Morel (1986 apud JUBRAN, 2006b, p. 311), esse trecho é 
segmentado em três partes. O primeiro, E1, diz respeito ao segmento anterior ao parêntese. O segundo, E2, corresponde ao parêntese propriamente dito e, por fim, o terceiro, E3 equivale ao segmento posterior ao parêntese, que dá continuidade ao tópico discursivo em pauta em E1. Delomier e Morel (1986 apud JUBRAN, 2006b, p. 311) esclarecem que $E$ se trata de um termo geral, correspondendo a um enunciado, que pode equivaler a uma frase, a uma unidade superior à frase ou ainda a um segmento de frase. Jubran considera essa elasticidade do conceito de enunciado como essencial para a análise da parentetização, uma vez que a constituição formal das inserções parentéticas é variável.

Um aspecto que permite depreender esclarecimentos sobre o estatuto da parentetização são as relações anafóricas entre E1 - E2 - E3. A ocorrência de elementos anafóricos pode estar presente em duas situações: uma em E3 e outra em E2. Nesse sentido, Delomier e Morel (1986 apud JUBRAN, 2006b) constataram em corpus de língua francesa que, quando existe anáfora em E3, o referente se encontra em E1, já quando há elemento anafórico em E2, ele faz remissão ao segmento E1 como um todo. Jubran (2006b) evidenciou os mesmos resultados no corpus do português brasileiro.

\section{O tópico e suas propriedades}

Como o objetivo deste trabalho é estudar os parênteses, entendido por Jubran (2006d) como "estratégia textual-interativa definível a partir da categoria de tópico discursivo" (p. 40), é preciso definirmos essa categoria de tópico discursivo. Além disso, o fato de trabalharmos com o plano do texto, nos obriga a adotar, necessariamente, categorias de estatuto textual, que têm de ser pertinentes ao enfoque pragmático da linguagem, e condizentes com a perspectiva textual-interativa assumida neste trabalho. ${ }^{3}$

Em sentido geral, o tópico é entendido como "aquilo acerca de que se está falando" (BROWN; YULE, 1983).

Com o objetivo de particularizar a noção de tópico discursivo, o Grupo de Organização Textual-Interativa definiu-lhe duas propriedades: a da centração

\footnotetext{
${ }^{3}$ Essa opção é feita porque comumente há uma distinção entre tópico frasal, de natureza sintática e restrita ao nível da frase, e tópico discursivo, cuja unidade é discursiva e não frasal, embora o tópico discursivo não elimine a frase, mas consideraa sempre relacionada a aspectos cotextuais e contextuais (MARCUSCHI, 2008).
} 
e a de organicidade (JUBRAN, 2006d; 2006d). Essas duas propriedades também são mencionadas por Fávero (1999). Já Marcuschi (2008) acrescenta a essas duas propriedades uma terceira: a da delimitabilidade.

Adotamos aqui a definição de tópico discursivo de acordo com Jubran (2006d), pois a autora faz algumas reconsiderações e complementações sobre as propriedades tópicas da centração e da organicidade, a fim de particularizar a noção de tópico discursivo. Assim, a centração abrange: i) a concernência: relação de interdependência entre os elementos textuais; ii) a relevância: proeminência desses elementos textuais na constituição desse conjunto referencial; e iii) a pontualização: localização desse conjunto em determinado ponto do texto (JUBRAN, 2006d). Já a organicidade, segunda propriedade tópica, é manifestada por relaçôes de interdependência tópica que se estabelecem simultaneamente em dois planos: no plano hierárquico (vertical) e no plano linear. $\mathrm{O}$ primeiro plano está relacionado com as dependências de super ou subordenação entre tópicos que se implicam pelo grau de abrangência com que são tratados na interlocução. Já o segundo plano, o linear, está relacionado com as articulações intertópicas em termos de adjacência ou interposições de tópicos na linha do discurso. A essa definição do princípio da organicidade, Jubran (2006d) acrescenta as articulações intratópicas.

Dadas as definiçôes das duas propriedades tópicas, é relevante mencionarmos que Jubran (2006b; 2006d) afirma que é a propriedade da centração tópica que funciona como parâmetro para o reconhecimento de inserçôes parentéticas dentro dos segmentos tópicos, já que as inserções têm natureza de desvio tópico.

\section{Chat - uma conversação síncrona escrita mediada por computador}

Partimos da definição de chat formulada por Barbosa-Paiva (2010), pois essa definição abrange a toda e qualquer modalidade de chat. Em seguida, trazemos também uma definição de chat educacional, caracterizado como um subgênero de chat.

O chat tem sido definido de forma diferente pela literatura. Diante desse contexto, Barbosa-Paiva (2010) propõe uma definição de chat, a fim de que haja uma complementação entre essas definições, e não um caráter de exclusão. Assim, a autora entende por chat. 
i) uma conversação escrita mediada por computador, que reflete as condições de produção ligadas ao tempo real ou on-line, ii) um novo gênero (digital), que apresenta características próprias que o singulariza e que está submetido às condições de produção da informática e da conexão em rede, entre outros aspectos relacionados à tecnologia digital (p. 49).

A CMC possibilitou também novas formas de comunicação na esfera educacional. Dentro desse cenário educativo, o chat tem recebido a denominação de chat educacional, que é definido por Marcuschi (2005, p. 28) como "interaçôes síncronas no estilo dos chats com finalidade educacional, geralmente para tirar dúvidas, dar atendimento pessoal ou em grupo e com temas prévios". Segundo Barbosa-Paiva (2009), o uso do chat se torna mais motivador quando se trata de ensino e aprendizagem de língua estrangeira, uma vez que possibilita ao aprendiz utilizar a língua-alvo em contextos reais de interação por meio da escrita (como é o caso do corpus que serão analisados neste artigo).

\section{Metodologia}

As sessões de chat analisadas pertencem a um curso de espanhol, intitulado "Español para Turismo" (EPT), que foi oferecido como um curso de extensão universitária de 30 h, no ano de 2007, na Universidade Estadual Paulista, no campus de Araraquara. O programa de chat utilizado foi o da plataforma Moodle.

O EPT foi oferecido a quatro turmas, em duas modalidades diferentes: dois na modalidade semipresencial e dois na modalidade a distância, e para cada uma das turmas foi nomeado um docente responsável. Esta pesquisa utiliza somente os dados referentes às turmas ministradas na modalidade a distância que tiveram como docente responsável os professores Irene e Marcos (nomes fictícios). Cada curso foi realizado de forma independente um do outro, mas simultaneamente. $\mathrm{O}$ curso da Profa. Irene apresentou 21 sessões de chats e o do Prof. Marcos, 31 sessões. Todas essas sessões, relativas aos dois cursos, são analisadas neste trabalho. A partir da FIG.1, podemos examinar a página de abertura do curso EPT: 


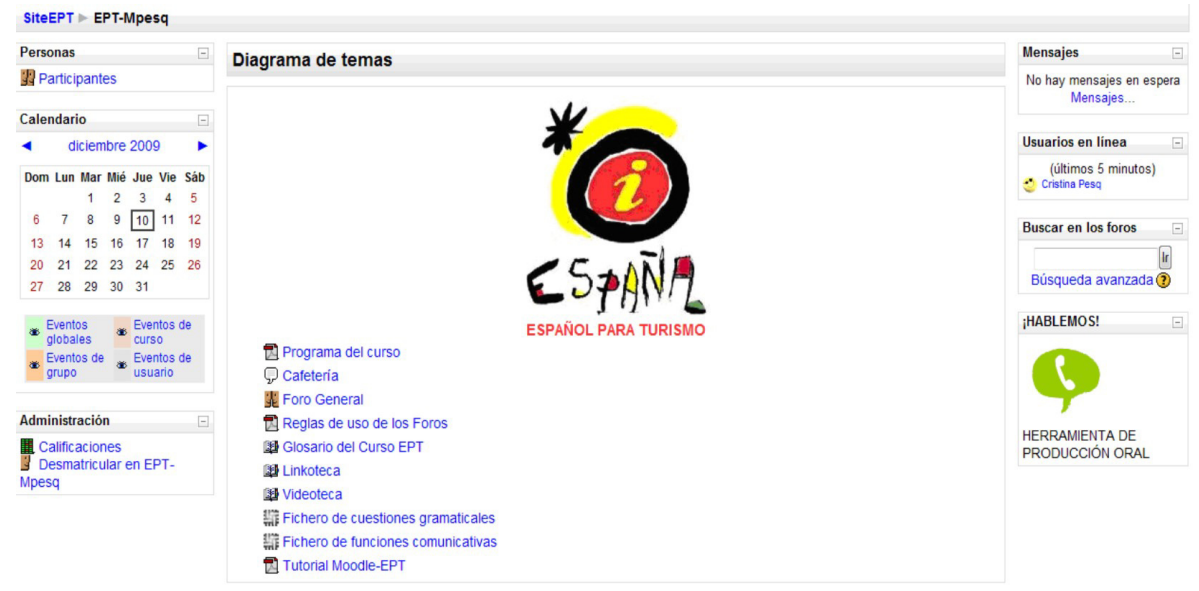

FIGURA 1 - Página de abertura do curso EPT

Podemos observar na FIG. 1 acima que, na tela principal do curso, na coluna central, ficam disponíveis aos seus participantes vários recursos, tais como o programa do curso, a cafeteria, o fórum geral, as regras de uso dos fóruns, o glossário, a linkoteca, a videoteca, o fichário de questôes gramaticais e o de questôes comunicativas. A FIG. 2 faz um recorte da tela principal da FIG. 1:

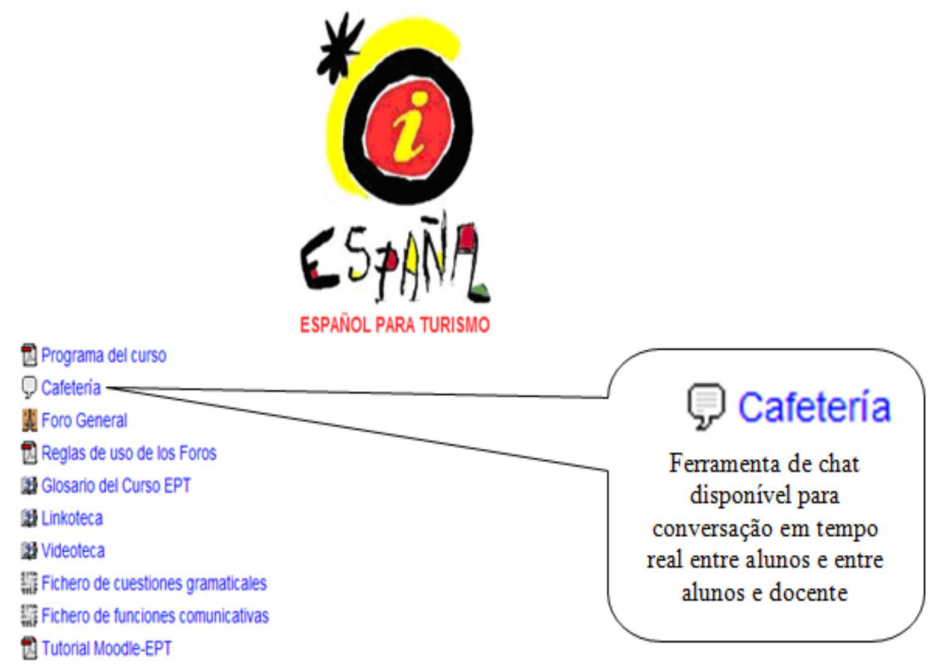

FIGURA 2 - O chat como um dos recursos disponíveis no EPT Fonte: BARBOSA-PAIVA, 2010, p. 14 
O programa de chat fazia parte do curso EPT e integrava as ferramentas disponíveis na plataforma Moodle. A FIG. 2 mostra, claramente, o lugar de acesso ao chat, para encontros em tempo sincrônico (real) entre aluno-aluno e entre professor-aluno. $\mathrm{O}$ chat foi uma das atividades obrigatórias do curso, que se baseou em uma metodologia de trabalho por tarefas, que, necessariamente, tinham de ser discutidas via chat entre alunos e entre alunos e professor.

Com relação ao tratamento do corpus, esclarecemos que não foram realizadas alterações nos textos conversacionais, uma vez que, como afirma Marcuschi (2005, p. 63), trata-se de "uma linguagem em seu estado natural de produção". Acrescentamos que os dados pessoais, inscritos nas sessões de chat, foram trocados a fim de preservar a identidade dos participantes.

No que concerne à investigação do tema proposto, ressaltamos que o percurso metodológico deste artigo seguiu os apontamentos de Jubran (2006a, 2007) para uma descrição textual-interativa da parentetização no chat educacional. Nesse sentido, o trabalho foi guiado pelos critérios de reconhecimento e delimitação de fatos parentéticos descritos por Jubran (JUBRAN, 1996a, 1996b, 2006a, 2006b), mencionados na fundamentação teórica deste artigo.

\section{Análise dos dados}

Um importante aspecto decorrente das análises dos dois cursos EPT, quanto à construção textual da estratégia de parentetização, é o fato de os participantes do curso EPT, na elaboração textual, reconhecerem, identificarem e delimitarem os parênteses, que, na maioria das vezes, recebiam marcas formais, tornando-se prototípicas.

Um aspecto que não poderia deixar de ser abordado nessa análise da parentetização é a possibilidade de haver não somente um tópico discursivo, mas, sim, dois ou mais tópicos sendo desenvolvidos simultaneamente, já que a sala virtual contava normalmente com vários participantes, e alguns podiam conversar entre si (os alunos digitavam todos ao mesmo tempo e, geralmente, dirigiam suas dúvidas ao / à professor / a).

A posição escolhida para o uso de marcadores formais de inserção parentética parece revelar que os participantes percebem um desvio tópico no momento da produção de seu texto, e decidem marcá-lo graficamente, levando à delimitação de fatos parentéticos. Partindo desses pressupostos, iniciamos a apresentação dos dados parentéticos por um excerto bastante revelador, retirado do curso da Profa. Irene: 
Excerto 1 (7a sessão do curso da Profa. Irene)

1. 10:19 Irene: Tabata, no te preocupes por el trabajo final. Te garantizo que será muy fácil para ti ... y para los que están cumpliendo las actividades y tareas ...

2. 10:19 Elisa: Hablando demasiado, sí....jejeje

3. 10:19 Carla: Tu no eras así....

4. 10:20 Irene: Eso sí, Elisa. Será no sólo un desafío sino sobretodo muy provechoso al final ...

5. 10:20 Tabata: ustedes estudian en UNESP?

6. 10:20 Paula: Aprenderemos mucho!

7. 10:21 Tabata: de dónde ustedes se conocen?

8. 10:21 Elisa: Hay un número mínimo de palabras a poner en el glosario?

9. 10:21 Irene: [;Con quien hablas, Tabata?]

10. 10:21 Elisa: Yo daba clases para ellas en otra facultad...

11. 10:21 Carla: Elisa fue mi profesora en la facultad....

12. 10:22 Elisa: Tabata...

13. 10:22 Tabata: de Carla y Elisa

14. 10:22 Irene: Por lo menos 3 palabras, Elisa. Con las definiciones ...

15. 10:22 Tabata: que Bárbaro!!! encontrar tu profesora aqui!

16. 10:23 Irene: ¡Qué bien! Ya había notado que algunos ya se conocían aquí ...

17. 10:23 Carla: Pero que me parezca le gusta mucho hablar también, Elisa....

18. 10:23 Elisa: Gracias Irene...

19. 10:23 Irene: [Paula, jsigues aquí?]

20. 10:24 Elisa: Sí, a mí me gusta Carla, no tanto como tú....jejeje

21. 10:24 Paula: Elisa me da clases también

22. 10:24 Paula: Si profesora

23. 10:25 Irene: ¡Qué buena notícia! Con relación a las actividades, ¿alguna duda más?

24. 10:26 Paula: No

25. 10:26 Bia: No

Dentro da porção textual (aqui não transcrita) em que ocorre o excerto acima, observamos o desenvolvimento de três tópicos simultaneamente: um sobre "trabalho final de curso", um sobre "colocação de palavras no glossário 
do curso EPT" e um sobre "conhecimento presencial entre alguns participantes do curso EPT". A presença de vários tópicos sendo discorridos ao mesmo tempo evidencia que à medida que os aprendizes vão tendo dúvidas com relação ao funcionamento do curso EPT, eles vão "lançando" perguntas à professora Irene. No desenvolvimento desses tópicos, a professora Irene encaixa dois parênteses (turnos 9 e 19) e ambos são considerados como inserções parentéticas, porque têm a peculiaridade do desvio tópico (no caso do excerto, desvio dos três tópicos) e se constituem como informações paralelas aos tópicos discursivos em curso. Essas inserçóes parentéticas materializam a presença do interlocutor no texto do chat e fazem referência a condiçôes enunciativas do discurso que garantem a possibilidade de intercâmbio verbal, preenchendo uma função fática, e são acentuadamente interacionais. Nesse sentido, os dois parênteses (turnos 9 e 19) têm uma dimensão pragmática, constituindo-se como um dos recursos pelos quais a atividade discursiva se projeta concretamente na materialidade linguística do texto. O segundo parêntese (turno 19), além de focalizar o interlocutor, apresenta também o foco no ato comunicativo, já que promove uma quebra do fluxo temático para, no interior do texto, focalizar um fator que poderia vir a perturbar o contato entre os participantes: se a aluna permanecia na sala ou não. As perguntas da professora Irene (nos turnos 9 e 19), com as respectivas respostas (turnos 13 e 22 respectivamente), configuram um par adjacente parentético, já que as respostas das aprendizes, conforme mostram os grifos, também integram os parênteses. Isso destaca a coparticipação dos interlocutores na construção do texto. Cabe ressaltar ainda que a professora Irene parece perceber as duas inserções parentéticas e considera apropriado o uso de marcadores formais como critério de reconhecimento e delimitação do fato parentético.

Outro caso de parêntese observado durante nossas análises é o de focalizadores da elaboração tópica, com uma subclassificação de focalizar o conteúdo tópico, conforme mostramos no excerto a seguir:

Excerto 2 ( $3^{a}$ sessão de chat do curso da Profa. Irene)

1. 11:10 Irene: ¿Habéis visto la infografía sobre el DNI electrónico? Para contestar a las preguntas hay que verla ...

2. 11:11 Elisa: Las preguntas que eran para contestar hasta el día 1/9 o de la primera tarea...

3. 11:12 Irene: Sí, Elisa, ¿cual es la duda?

4. 11:13 Bia: ahora estoy entendiéndome con esto....jejejeje 
5. 11:13 Irene: Se trata de un Cuestionario que necesito para conocer el grupo (para conocer el perfil profesional, en dónde vive, qué es lo que hace, si ha tenido experiencia en otro curso virtual etc)

6. 11:14 Irene: ¡Eso me alegra muchísimo¡, Barbara

7. 11:14 Elisa: Aquellas preguntas que recibimos por e-mail que estaban en Portugués yo salvé....entonces está correcto.

O trecho indica que o segmento sublinhado é considerado inserção parentética e, pelo fato de focalizar o conteúdo tópico (questionário para conhecer o grupo), mantém proximidade com o tópico discursivo em desenvolvimento. De acordo com Jubran (2006b), os parênteses desse tipo "atenuam a propriedade de desvio tópico particularizadora da parentetização" (p. 328). A inserção parentética do excerto é identificada, sobretudo, pelas marcas formais do uso de sinal de parênteses $(())$ que a professora Irene escreve graficamente, sugerindo sua percepção do fato parentético. Notamos que a função do segmento parentético é de esclarecimento, uma vez que ele detalha o dado exposto no enunciado do turno 5 , atendendo à regra de clareza. Isso mostra que o foco do parêntese diminui a expressão do processo interativo na materialidade linguística do texto. $\mathrm{O}$ excerto abaixo nos mostra que as três inserções parentéticas integram a classe de parêntese com o foco no locutor:

Excerto 3 (17 a sessão de chat do curso da Profa. Irene)

1. 10:12 Marcio: Si están hablando cuanto al horario de la cafetería, me pongo de la misma manera que mis compañeras! Es dificil este horario!

2. 10:13 Amanda: Si, pero pienso que tiempo también es una questión de organización...

3. 10:13 Paula: A mi también...

4. 10:13 Cintia: Yo recibi de pronto la contestación de una agencia,(que vergonha) pero no conseguia enviarla y Tabata ayudó.

5. 10:13 Irene: ¿No os gusta este horário? os voy a dar otras opciones para el último encuentro ...

6. 10:14 Cintia: Tengo dificuldad con el ordenador...

7. 10:14 Elisa: domingo....jejeje

8. 10:14 Irene: [No lo había percibido, Citinha]

9. 10:14 Irene: ¿Te parece que está bien el domingo, Elisa?

10. 10:15 Irene: Para un café sólo ... 
O excerto mostra que os tópicos discursivos são sobre "o horário dos encontros via chat" e sobre "a resposta das agências espanholas às perguntas dos aprendizes do curso EPT". No desenvolvimento simultâneo desses dois tópicos, Cintia encaixa um parêntese "(que vergonha)", exatamente no meio de seu turno, no qual ela escrevia sobre a resposta da agência espanhola à sua pergunta. O desvio parentético é evidenciado nesse trecho pelo fato de o segmento não ser concernente ao tópico relevante do segmento-contexto, porque desloca o foco desse segmento, sobre "resposta das agências espanholas" fazendo-o voltar-se para a própria escrevente. Nesse ponto, observamos que a escrevente se introjeta no texto que produz. Ela insere um comentário avaliativo ao receber a resposta da agência, atestando envolvimento com o tópico discursivo que desenvolve e com a própria situação real de uso da linguagem. No turno 6, Cintia novamente se introjeta no texto que produz, inserindo um parêntese de comentário avaliativo de sua dificuldade em usar o computador. A professora Irene responde a esse parêntese com outra inserção parentética "[No lo habia percibido, Citinha]". Dessa forma, a professora insere um comentário para declarar à interlocutora a sua falta de conhecimento e de percepção sobre a dificuldade da aluna (Cintia) em lidar com o computador. Assim, os turnos 6 e 8 configuram um par adjacente parentético, destacando a coparticipação dos interlocutores na construção textual. Notamos que os parênteses (dos turnos 4 e 8) apresentam marcas formais prototípicas de elemento inserido na delimitação das inserçōes parentéticas: no fato parentético do turno 4 há os sinais de pontuação dos parênteses $(())$ e no do turno 8 , os colchetes ( [ ] ). Já, no turno 6, fica ausente a marca formal prototípica e, nesse caso, a propriedade identificadora do parêntese foi o "critério primeiro" de identificação de inserções parentéticas, conforme exposto por Jubran (2006b; 1996): o desvio tópico. O próximo excerto, retirado do curso da professora Irene, mostra outro caso de parentetização:

Excerto 4 (13a sessão do curso da Irene)

1. 10:49 Bia: tienes msn?

2. 10:50 Tabata: si, tengo

3.10:50 Tabata: thatigsa@hotmail.com

4. 10:50 Bia: vale

5. 10:50 Bia: gracias

6. 10:50 Tabata: jejejeje..ya hicimos nuestra clase de la semana! jejeje 
7. 10:51 Tabata: no necesitamos venir en la proxima semana ahora... jejejejejejejejejejejejeje

8. 10:51 Bia: es verdad....jejejejeje

9. 10:51 Bia: no había pensado en esto jejeje

10. 10:52 Bia: ya hicimos nuestra parte

11. 10:52 Tabata: me "agriega” (es así que dice?) en MSN y otras vces charlamos

12. 10:52 Tabata: si... piensas, solamente nosotras nos quedamos aca...justo las que no vienen en la proxima semana! jejeje

13. 10:53 Bia: ya te agregué...el mío es xxxx2@hotmail.com....si quieres intentar de ahí....pq este programa aquí es horrible jejejeje........eso es......jejejejeje

O excerto apresenta uma inserção parentética, relacionada à formulação linguística do tópico, como podemos observar, no turno 11, na parte sublinhada. No excerto, há um diálogo entre duas alunas, as quais conversam simultaneamente sobre dois tópicos discursivos: 1) "adicionar uma a outra no MSN" e 2) "ao conversar nessa sessão de chat, as aprendizes achavam que já haviam cumprido o compromisso de participar do encontro virtual na sala de chat". Ao interromper momentaneamente o tópico 1, Tabata encaixa uma pergunta, em forma de inserção parentética "(es asi que dice?)", a respeito de uma dúvida quanto ao uso adequado do verbo "agregar", retomando imediatamente o tópico em curso. A aprendiz resolve marcá-la também com marcas formais de elemento inserido, o que mostra uma "consciência" de encaixe de elemento desviante da centração tópica. Na inserção parentética, a escrevente Tabata chama a interlocutora, Bia, para dentro do texto com a intenção de pedir-lhe ajuda na verificação do uso apropriado do referido verbo. Bia parece concordar com a colega a respeito do uso da palavra, pelo fato de usá-la no seu turno (turno 13). Essa inserção parentética encaixada no tópico em desenvolvimento evidencia uma especificidade do texto do chat de simultaneidade entre planejamento e verbalização. $\mathrm{O}$ excerto a seguir mostra uma inserção parentética focalizadora do ato comunicativo, cuja categoria parece promover um grau máximo de desvio tópico:

Excerto 5 (17a sessão do curso da Profa. Irene)

1. 10:22 Cintia: hola,Livia.

2. 10:22 Paula: Hay muchas informaciones y cosas que yo jamás había pensado

3. 10:22 Elisa: Hola Livia. 
4. 10:22 Amanda: Hola, Livia !ya estaba te echando de menos...

5. 10:22 Paula: Hola, Livia!

6. 10:22 Irene: Muy bien, Amanda ... y será más o menos eso lo que vamos a hacer esta semana ...

7. 10:23 Irene: Lo que falta es algo de OCIO Y GASTRONOMÍA ...

8. 10:23: Amanda Epti salió de la sala

9. 10:24 Irene: Al final del curso todos seráis capaces de preparar un viaje completo a un turista que desea hacer turismo en España (con poco o mucho dinero)

10. 10:24: Amanda Epti entró a la sala

11. 10:24: Paula Epti salió de la sala

12. 10:24: Marcio Epti salió de la sala

13. 10:24: Elisa Epti salió de la sala

14. 10:24: Livia Epti salió de la sala

15. 10:24: Cintia Epti salió de la sala

16. 10:24: Irene Profe EPTI salió de la sala

17. 10:25 Amanda: ? Verdad?

18. 10:26: Cintia Epti entró a la sala

19. 10:26: Irene Profe EPTI entró a la sala

20. 10:26 Amanda: Me encanta saber más sobre las comidas típicas de España....

21. 10:26 Irene: [ops, conexión]

22. 10:26 Irene: Seguro disfrutaréis de esa semana ...

23. 10:27 Amanda: Me alegro

Podemos observar que, no turno 8 e nos turnos de 10 ao 16, houve anunciada a marca automática de saída dos participantes do curso EPT. Já nos turnos 10 e 18 aparecem as marcas automáticas de entrada dos interagentes na sala virtual. Notamos que a professora Irene (no turno 21, conforme mostra o grifo) indica, por meio de uma parentetização ([ops, conexión]), a ocorrência de um problema na rede, considerada relevante naquele momento para dar prosseguimento do ato comunicativo, uma vez que esse problema afeta o contato entre os participantes, devido à conversação ser mediada por computador conectado à internet. Além disso, ela procura mencionar, por meio do parêntese, que a saída foi ocasionada por problema técnico, e não pela 
vontade dos internautas. Nesse sentido, o parêntese não tem nenhuma concernência com o tópico sobre o qual se escrevia, o que a professora Irene parece perceber ao usar as marcas formais na delimitação do elemento inserido. Ele provoca o "apagamento" do tópico em curso, que, com as marcas automáticas de saída, configura um conjunto parentético de maior complexidade, pois o parêntese (do turno 21) foi ocasionado pelas sequências de marcas automáticas de saída. O parêntese evidencia condições de uma situação específica: a necessidade da tecnologia (conexão em rede) para se estabelecer uma conversação mediada por computador. Cabe ressaltar que as marcas automáticas da plataforma Moodle não são consideradas por nós, neste trabalho, como inserções parentéticas, uma vez que essas marcas são denominadas, nesta pesquisa, como primeiro ou quinto momento interativo do chat.

A análise do corpus revelou que a aplicação das relações anafóricas entre E1 - E2 - E3 pode ocorrer de forma um pouco distinta da maneira como descrevem Jubran (2006b) e Delomier e Moriel (1986 apud JUBRAN, 2006b) em corpus de língua falada. Isto parece estar relacionado com as condições de produção dos chats educacionais investigados, em que, normalmente, há várias pessoas escrevendo ao mesmo tempo, e, assim, as mensagens vão aparecendo na tela, formando o texto com diversos turnos. Dessa forma, o sistema de turnos do chat é diferente do da conversação face a face. No chat, cada turno corresponde a uma mensagem escrita e enviada à plataforma, por meio da tecla enter. Nesse sentido, pode ocorrer que a inserção parentética esteja em um único turno e o elemento que a antecede não seja o E1 propriamente dito, mas, sim, outro turno de outro interlocutor. Assim, o E1 pode estar mais "distante" do E2, fato que pode ser bem observado no excerto (1). O mesmo pode ocorrer com a localização do E3. Com isso, observamos que, em algumas ocorrências do texto do chat educacional, tornase "mais difícil encaixar" o esquema das relações anafóricas conforme foram descritas no corpus de texto falado (francês e o português). Nessa linha, diríamos que, em alguns casos, não é tão aplicável esse critério das relações anafóricas no corpus investigado, para depreender e esclarecer elementos inseridos. Essa questão se explica também porque, no chat, há normalmente vários tópicos sendo desenvolvidos e assim pode acontecer de o referente E3 fazer parte de um tópico diferente do que estava sendo desenvolvido em E1, como pudemos observar o excerto (2). Ressaltamos, no entanto, que, no corpus, também ocorrem as relaçôes E1 - E2 - E3 em um mesmo turno, por 
exemplo, os excertos (3) (o parêntese do turno 4) e o (4). Dessa maneira, nesses excertos mencionados são observadas as relações anafóricas ("típicas"), conforme os apontamentos de Jubran (2006b) e Delomier e Morel (1986 apud JUBRAN 2006b).

Considerando algumas observações que Jubran (2006b) faz sobre a parentetização no texto escrito prototípico, já que o seu foco eram situações de diálogo face a face, propomos, na TAB. 1, uma comparação entre o texto escrito prototípico e o texto ora analisado no que concerne à ocorrência da parentetização:

\section{TABELA 1}

Diferenças entre a parentetização do chat do EPT e do texto escrito prototípico de acordo com Jubran (2006)

\begin{tabular}{l|l}
\hline $\begin{array}{l}\text { Parentetização caracterizada no texto } \\
\text { escrito prototípico por Jubran (2006) }\end{array}$ & Parentetização observada nesta pesquisa (chat) \\
\hline $\begin{array}{l}\text { O texto escrito prototípico é planejável } \\
\text { com antecedência (é pensado, projetado } \\
\text { e lapidado antes da versão final) }\end{array}$ & $\begin{array}{l}\text { O texto escrito do chat é relativamente planejável. } \\
\text { O escrevendo pode reformulá-lo no processo de } \\
\text { produção. No entanto, o meio exige que seja } \\
\text { rápida a digitação do texto e, por isso, há, no chat, } \\
\text { algumas estratégias de construção textual que não } \\
\text { são vistas na escrita prototípica, por exemplo, } \\
\text { a correção, a repetição, a hesitação e outras }\end{array}$ \\
$\begin{array}{l}\text { O modus sintático prevalece sobre o } \\
\text { pragmático }\end{array}$ & $\begin{array}{l}\text { O modus pragmático tende a prevalecer sobre o } \\
\text { sintático }\end{array}$ \\
\hline $\begin{array}{l}\text { Não se esperam parênteses que promovam } \\
\text { cortes sintáticos e nem que se intercalem } \\
\text { em certas fronteiras em que uma inserção } \\
\text { poderia romper estruturas canônicas }\end{array}$ & $\begin{array}{l}\text { Devido à natureza do chat, verificamos a inserção } \\
\text { parentética intercalando estruturas canônicas }\end{array}$ \\
\hline $\begin{array}{l}\text { Estão bloqueadas as funçáes dos parênteses } \\
\text { focalizadores da formulação linguística } \\
\text { do tópico discursivo, uma vez que } \\
\text { refletem o processamento on-line da fala }\end{array}$ & $\begin{array}{l}\text { Há parênteses com o foco na formulação linguística } \\
\text { do tópico }\end{array}$ \\
\hline
\end{tabular}

Os aspectos apresentados pela TAB. 1 sugerem algumas das particularidades do texto escrito do chat, analisado nesta investigação, com relação à parentetização. 


\section{Considerações finais}

Retornando aos objetivos deste artigo, os dados analisados permitem observar a parentetização como uma estratégia de construção textual-interativa do chat educacional, constituindo uma das regularidades dos processos de construção textual-interativa. As inserções parentéticas aparecem inscritas na superfície textual do chat educacional como marcas do processamento formulativo-interacional na materialidade linguística do texto. Nesse sentido, verificamos que a parentetização faz parte da atividade de formulação do chat educacional.

Tivemos, portanto, a ocorrência da manifestação das quatro grandes classes de parênteses elaboradas por Jubran (2006b) e da classe que configura o foco no locutor e no interlocutor ao mesmo tempo, conforme apresentamos na fundamentação teórica deste artigo. Nesse sentido, no corpus, houve o foco na elaboração tópica do texto, no locutor, no interlocutor, no ato comunicativo e parêntese com foco no locutor e no interlocutor. Além disso, verificamos ainda no corpus, que um parêntese pode focalizar, simultaneamente, classes diferentes, como focar o interlocutor e o ato comunicativo em uma única inserção parentética.

A análise do chat educacional revelou também que à propriedade de desvio tópico, identificadora de inserções parentéticas, juntam-se marcas formais prototípicas de elemento inserido para identificação dos parênteses (JUBRAN, 2006b). Essas marcas foram os sinais de parêntese ( ( ) ), de colchete ( [ ] ) e de chaves ( \{\} ). Houve também ausência de marcas formais de inserção parentética. Concluímos, portanto, que as marcas formais de inserção parentética, nos dois chats educacionais em análise, tornam-se prototípicas, funcionando como um critério fundamental para o reconhecimento e delimitação de fatos parentéticos, pois há a possibilidade de ocorrência de mais de um tópico sendo desenvolvido no chat educacional, devido às condições de produção desse gênero. ${ }^{4}$ Além disso, o texto do chat não conta, por exemplo, com traços típicos do texto falado para auxiliar na precisão das fronteiras das inserçôes parentéticas, como as marcas prosódicas, a mudança na velocidade e na tessitura, as pausas e as alteraçóes na pronúncia dos parênteses.

${ }^{4}$ Geralmente a sessão de chat educacional contava com vários participantes que escreviam simultaneamente. Assim, poderia ocorrer mais do que um tópico discursivo sendo desenvolvido. 
É significativo mencionar que a posição escolhida para o uso de marcadores formais de inserção parentética parece revelar que os participantes percebem um desvio tópico, no momento da produção de seu texto, e decidem marcá-lo graficamente, levando à delimitação de fatos parentéticos.

Observamos ainda que as inserções parentéticas não podem ser consideradas como "desvios descartáveis do texto" do chat educacional (JUBRAN, 2006b). A parentetização se mostra como uma estratégia textualinterativa muito produtiva no chat educacional, pois apresentou um papel relevante no estabelecimento da significação de base informacional. No corpus, os fatos parentéticos estavam sempre orientados para a compreensão e inteligibilidade do texto, com vistas à produção de um texto que fosse capaz de funcionar comunicativamente dentro do contexto e das condiçôes de produção em que foi gerado o chat educacional investigado. Além disso, as inserçōes parentéticas puderam acrescentar informaçōes que eram consideradas, pelos escreventes, como importantes naquela situação comunicativa. Isso porque, por meio dos fatos parentéticos, os participantes se introjetavam no texto que produziam, pediam a presença do interlocutor, mencionavam o ato comunicativo em curso e faziam comentários sobre o que se escrevia e sobre como se escrevia.

Para enriquecer e complementar os resultados da presente análise e assim melhor compreender a parentetização na construção textual do chat educacional, é nosso propósito nos ocuparmos, em uma próxima oportunidade, da constituição formal dos parênteses.

Retomando o ponto de partida deste artigo, buscamos oferecer uma descrição de uma estratégia de construção textual-interativa (no caso, a parentetização), no chat educacional, de modo a contribuir para o levantamento e entendimento de um processo de construção textual que se mostrou regular no processamento dos procedimentos de elaboração textual. Nesse sentido, este trabalho pode contribuir para o estudo da construção textual-interativa do chat educacional, um gênero novo que nasceu com as novas tecnologias de informação e comunicação.

Para finalizar, mencionamos que procuramos abarcar a parentetização, no chat educacional, porque a consideramos significativa para particularizar a construção do texto do chat, sob uma perspectiva teórica que privilegia o seu processamento formulativo-interacional. 


\section{Referências}

BARBOSA-PAIVA, C. L. Estratégias de construção textual do chat escrito em espanhol como língua estrangeira. 238 f. Dissertação (Mestrado em Linguística e Língua Portuguesa) - Faculdade de Ciências e Letras, Universidade Estadual Paulista Júlio de Mesquita Filho, Araraquara, 2010.

BARBOSA-PAIVA, C. L. Uso do chat na sala de aula de língua espanhola: uma proposta a partir da análise do gênero. In: SOTO, U.; MAYRINK, M. F.; GREGOLIN, I. V. (Org.). Linguagem, educação e virtualidade. São Paulo: Cultura Acadêmica, 2009. p. 225-240. Disponível em <http://www.culturaacademica. com.br/downloads/\%7B7FB2BEA6-9254-432A-803B-B4C1AC031230\%7 D_Linguagem_educacao_e_virtualidade-BxRes.pdf $>$. Acesso em: 16 ago. 2010. BROWN, G.; YULE, G. Discourse analysis. Cambridge: Cambridge University Press. 1983. 288p.

CASTILHO, A. T. A lingua falada no ensino de português. São Paulo: Contexto, 1998.

CRYSTAL, D. A revolução da linguagem. Tradução de Ricardo Quintana; consultoria, Yonne Leite. Rio de Janeiro: Jorge Zahar, 2005. 151p.

CRYSTAL, D. El lenguaje e Internet. Traducción española de Pedro Tena. Madrid: Cambrigde University Press, 2002. 304p.

FÁVERO, L. L.; ANDRADE, M. L. C. V. O.; AQUINO, Z. G. O. Correção. In: JUBRÁN, C. C. A. S.; KOCH, I. G. V. (Org.). Gramática do português culto falado no Brasil. Campinas: Editora da Unicamp, 2006. v. 1. Construção do texto falado. p. 255-273.

FÁVERO, L. L. O tópico discursivo. In: PRETI, D. (Org.). Análise de textos orais. 4. ed. São Paulo: Humanitas FFLCH/USP, 1999. p. 33-54.

JUBRAN, C. C. A. S. Introdução - A perspectiva textual-interativa. In: JUBRAN, C. C. A. S.; KOCH, I. G. V. (Org.). Gramática do português culto falado no Brasil. Campinas: Editora da Unicamp, 2006a. v. 1. Construção do texto falado. 557p.

JUBRAN, C. C. A. S. Parentetização. In: JUBRAN, C. C. A. S.; KOCH, I. G. V. (Org.). Gramática do português culto falado no Brasil. v. 1. Construção do texto falado. Campinas: Editora da Unicamp, 2006b. p. 301-357.

JUBRAN, C. C. A. S. Tópico discursivo. In: JUBRAN, C. C. A. S.; KOCH, I. G. V. (Org.). Gramática do português culto falado no Brasil. Campinas: Editora da Unicamp, 2006c. vol. 1. Construção do texto falado. p. 89-132. 
JUBRAN, C. C. A. S. Revisitando a noção de tópico discursivo. Cadernos de Estudos Linguisticos. Campinas, v. 48, n. 1, p. 33-41, 2006 d.

JUBRAN, C. C. A. S. Uma gramática textual de orientação interacional. In: CASTILHO, A. T. et alii (Org.). Descrição, história e aquisição do português brasileiro. Campinas: Pontes, 2007. p. 312-327.

JUBRAN, C. C. A. S. Para uma descrição textual-interativa das funções de parentetização. In: KATO, M. (Org.). Gramática do português falado. Campinas: Editora da Unicamp; São Paulo: FAPESP, 1996a. v. 5 Convergências. p. 339-354.

JUBRAN, C. C. A. S. Parênteses: propriedades identificadoras. In: CASTILHO, A. T.; BASÍLIO, M. (Org.). Gramática do português falado. Campinas: Editora da UNICAMP; São Paulo: FAPESP, 1996b.

JUBRAN, C. C. A. S. Funçōes textuais-interativas dos parênteses. In: NEVES, M. H. de M. (Org.). Gramática do português falado. v. VII Novos Estudos. São Paulo: Humanitas/FFLCH/USP; Campinas: Editora da Unicamp, 1999.

JUBRAN, C. C. A. S. O metadiscurso entre parênteses. Estudos Linguísticos, São Paulo, v. 38, n. 3, p. 293-303, 2009. Disponível em: <http://www.gel.org.br/ estudoslinguisticos/volumes/38/EL_V38N3_23.pdf>. Acesso em: 20 jan. 2011.

KOCH, I. G. V. A inter-ação pela linguagem. 8. ed. São Paulo: Contexto, 2003. 143p. KOCH, I. G. V. O texto e a construção dos sentidos. 6. ed. São Paulo: Contexto, 2002. 165 p.

MARCUSCHI, L. A. Gêneros textuais no ensino de língua. In: MARCUSCHI, L. A. Produção textual, análise de gêneros e compreensão. São Paulo: Parábola Editorial, 2008. p. 146-225.

MARCUSCHI, L. A. Gêneros textuais emergentes no contexto da tecnologia digital. MARCUSCHI, L. A.; XAVIER, A. C. (Org.). Hipertexto e gêneros digitais: novas formas de construção do sentido. 2. ed. Rio de Janeiro: Lucerna, 2005. p. 13-67.

NEVES, M. H. de M. Ensino de lingua e vivência de linguagem: temas em confronto. São Paulo: Contexto, 2010. 286p.

RODRÍGUEZ ILLERA, José Luis; ESCOFET ROIG, Ana. La enseñanza y el aprendizaje de competencias comunicativas en entornos virtuales. In: COLL, César; MONEREO, Carles. (Org.). Psicología de la educación virtual: aprender y enseñar con las Tecnologías de la información y la Comunicación. Madrid: Morata, 2008. p. 368-385.

Recebido em 28/02/2011. Aprovado em 11/05/2011. 